\title{
Experimental studies related to autoimmunity in myasthenia gravis
}

\author{
B. M. KAUFMAN, G. RUSHWORTH, AND R. WRIGHT \\ From the Nuffield Department of Medicine, Radcliffe Infirmary, Oxford, and the Department of Clinical \\ Neurophysiology, Churchill Hospital, Oxford
}

The possibility that autoimmune mechanisms might be a factor in the pathogenesis of myasthenia gravis has been proposed on a number of grounds. Clinically, the association of myasthenia gravis with other putative autoimmune diseases has been cited as favouring such a hypothesis. Immunological evidence includes the demonstration of circulating autoantibodies to muscle in the sera of a number of patients with myasthenia gravis (Strauss, Seegal, Hsu, Burkholder, Nastuk, and Osserman, 1960; Beutner, Witebsky, Ricken, and Adler, 1962; Strauss, Smith, Cage, Van Der Geld, McFarlin, and Barlow, 1966), also reacting with 'myoid' cells in the thymus (Van Der Geld, Feltkamp, and Oosterhuis, 1964; Van Der Geld and Strauss, 1966). Experimentally, it is claimed that the injection of heterologous muscle homogenates into guinea-pigs will produce circulating antibody reacting with muscle and various components of the thymus, and also a myasthenialike myopathy which can be detected electromyographically (Goldstein and Whittingham, 1966).

The present report consists of an experimental study in the production of myasthenia gravis by immunological means in animals. Histological and histochemical studies of thymus are also described, with particular reference to the nature of the 'myoid' cells of the thymus.

\section{IMMUNOLOGICAL STUDIES}

Several attempts have been made to produce a disease resembling myasthenia gravis in experimental animals by immunological means. Germinal follicles similar to those seen in myasthenia gravis develop in the thymus of animals when antigen is injected directly into it (Marshall and White, 1961a, b; Blau and Waksman, 1964; Sherman, Adner, and Dameshek, 1964, 1965), but this has not been associated with obvious clinical disease of muscle.

Simpson (1966) has reported early experiments in which mice were immunized with homologous muscle homogenates without producing evidence of a myasthenia-like disease.
Namba, Himei, and Grob (1964) and Namba and Grob (1966) isolated a ribonucleoprotein from muscle which reacted avidly with d-tubocurarine and acetylcholine, but repeated injection of this fraction together with Freund's adjuvant into rabbits did not result in muscle damage, although antibodies identical with those found in the sera of patients with myasthenia gravis were produced. Parkes (1966) found no apparent functional disturbance of muscle after the repeated injection of homologous muscle with adjuvant into rats, although atrophy of muscle fibres did develop in some of the immunized animals. Tolnai (1966) has found structural changes in muscle, produced by immunizing mice with homologous muscle, but there was no evidence of muscle wasting or weakness. On the other hand, Tal and Liban (1962) claimed to be able to produce muscle wasting and weakness in rabbits and guinea-pigs by the repeated injection of homologous and heterologous muscle in Freund's adjuvant. More recently, Goldstein and Whittingham (1966) observed histological abnormalities in muscle and thymus, and electromyographic changes resembling myasthenia gravis in guinea-pigs immunized with heterologous muscle in adjuvant. We have reexamined the problem using a similar approach to that of Goldstein and Whittingham, with more extensive electromyographic studies.

\section{MATERIALS AND METHODS}

MUSCLE HOMOGENATES Fresh gastrocnemius muscle from a calf was homogenized by the method described by Goldstein and Whittingham (1966). Fat and connective tissue were removed, the muscle was cut into small pieces, and homogenized for two minutes $(1 / 5 \mathrm{wt} / \mathrm{vol})$ in cold phosphate-buffered saline $(0.15$ molar, $p H \mathbf{7} \cdot 2)$ in a Virtis Homogenizer at $4^{\circ} \mathrm{C}$. The resulting homogenate was spun at 3,000 $\times g$ in an MRC refrigerated centrifuge at 0 to $4^{\circ} \mathrm{C}$, and the resulting supernatant emulsified with an equal volume of complete Freund's adjuvant (Difco Ltd.).

IMMUNIZATION SCHEDULES Hartley MRC guinea-pigs, 6 to 9 months old, were immunized with the fresh muscle 
homogenate in complete Freund's adjuvant. Thirteen animals were given an injection of $0.1 \mathrm{ml}$. homogenate into each hind foot-pad. Five animals received injections of complete Freund's adjuvant alone, and 10 normal animals served as additional controls. Six animals received a booster dose of antigen into the foot-pads, two weeks after initial immunization.

Young guinea-pigs were used in this experiment. In a separate earlier experiment 12 to 18 month-old guineapigs of the same strain had been immunized with calf muscle (six animals), calf thymus (eight animals), and human gastrocnemius muscle (four animals) by foot-pad injection.

ELECTROMYOGRAPHIC STUDIES Two weeks after immunization the animals were anaesthetized with Nembutal $(0.1 \mathrm{mg} / \mathrm{kg}$ body weight) and at the same time received atropine $(0.04 \mathrm{mg} / \mathrm{kg}$ body weight) by intraperitoneal injection. Each animal was supported on its back and kept warm by means of a hot water bottle. One forelimb was strapped to a plastic support held rigid by clamps, and single-core stimulating needle electrodes were inserted into the axilla in the region of the brachial plexus. Needle recording electrodes were inserted into the flexors of the palm (single-core co-axial) and flexor digitorum (doublecore co-axial), and the animal earthed. Electrodes were manipulated to achieve a maximal response and fixed in position. Square pulse waves of 0.05 second's duration were delivered, and threshold and maximal voltages for the muscle determined.

The muscle electrical response was visualized on an oscilloscope and photographed as a stationary spot on slow-moving photographic paper $(40 \mathrm{~mm} / \mathrm{sec})$. All stimuli were delivered at supramaximal voltage, usually twice the maximal voltage. Trains of stimuli were delivered at rates of $1 / \mathrm{sec}, 3 / \mathrm{sec}, 10 / \mathrm{sec}$, and $50 / \mathrm{sec}$, and a further train of stimuli at $1 / \mathrm{sec}$ was then made immediately after tetanization, to assess electrode shift. This schedule of stimulation was then repeated 10 minutes and 30 minutes after an intraperitoneal injection of $0.2 \mathrm{mg} / \mathrm{kg}$ neostigmine. The effects of curarization, 15 minutes after injection of $2 \mathrm{mg}$ d-tubocurarine intraperitoneally, were also studied.

Random recordings of intramuscular temperature were made using a needle thermocouple.

HISTOLOGICAL STUDIES Animals were killed while still anaesthetized, by intracardiac puncture and exsanguination. Striated muscle from the thigh and chest wall, and cardiac muscle were removed and fixed in $10 \%$ formol saline; sections were later stained with haematoxylin and eosin.

IMMUNOLOGICAL TESTS Specimens of serum from immunized and control animals were stored at $-20^{\circ} \mathrm{C}$ for subsequent immunological tests. All sera were tested at least twice.

Immunofluorescence staining A modification of the indirect technique was used (Coons, 1954). Sections of calf thymus, calf and rat skeletal and heart muscle were sectioned in a cryostat at $-20^{\circ} \mathrm{C}$, to a thickness of 6 to $8 \mu$. The sections were covered with serum, diluted $1: 5$ in Coon's buffer for 10 minutes, washed in buffer for 20 minutes, and then covered with anti-guinea-pig globulin conjugated with fluorescein isothiocyanate (Baltimore Biologicals Ltd.) at a dilution of 1:10 for 10 minutes. They were then washed for 45 minutes in two changes of buffer. Greater concentrations of conjugate resulted in $c$ non-specific staining.

Gel diffusion Sera were also tested by the Ouchterlony technique (1953) using $1 \%$ oxoid ion agar in $0.1 \mathrm{M}$ phosphate buffered saline at $p \mathbf{H} 7 \cdot 2$. Calf-muscle homogenate, prepared as previously described, was placed in a. central well $4 \mathrm{~mm}$ in diameter, and the undiluted test sera in wells at a distance of $6 \mathrm{~mm}$ from the central well.

\section{RESULTS}

ELECTROMYOGRAPHIC FINDINGS Electrode move- ® ment was a continual problem, even when the guinea- ڤึ pig's limbs and the electrodes had been fixed in $\vec{\circ}$ position to rigid supports. This was presumably due to the isotonic nature of the muscle contraction. $\vec{\omega}$ Small displacing movements and rotation of a double-core co-axial rotating electrode within a muscle (flexor digitorum) were found to give? alterations in spike height varying from $-55 \%$ to $N$ $+125 \%$. Electrode displacement was most marked at the higher rates of stimulation.

Small changes in spike height occurred in both directions, in both normal and immunized animals at rates of stimulation of $1 / \mathrm{sec}, 3 / \mathrm{sec}$, and 10/se Occasionally changes in spike height as large ag $-33 \%$ to $+50 \%$ occurred. Curarized muscle, i⿱宀 comparison, showed consistent large decrements if $\overrightarrow{\vec{H}}$ the height of muscle response at all rates of stimu lation in both normal and immunized animals. At rates of $1 / \mathrm{sec}$ this averaged $-38 \%$, at $3 / \mathrm{sec},-57.5 \%$, and at $10 / \mathrm{sec},-49 \%$. Neostigmine produced no demonstrable difference in the height of the muscle response in normal or immunized animals, and no increased sensitivity to curare was seen in the immunized animals.

At rates of stimulation of $50 / \mathrm{sec}$ the initial electrical responses of the muscle often showed bizarre changes, again attributable to electrode displacement. These were more often seen in the flexor digitorum than the palmar flexors. Later muscle responses, however, generally showed a progressive decrement in height and were not associated with electrode displacement, probably as the muscle had now attained a constant contraction length (Fig. 1). Comparative measurements of decrement in the height of muscle response between immunized and control animals were made by comparing the times taken for a $25 \%$ decrement in spike height and the percentage decrement in spike height after 3 seconds stimulation. Wide variations in these parameters occurred among the various groups of animals, but no significant differences could be found between immunized and control animals, nor 
Curarised Guinea-pig

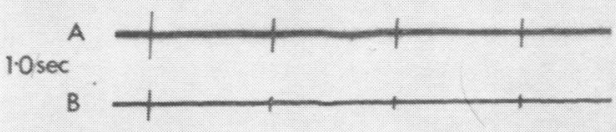

$3 \mathrm{sec}$

B
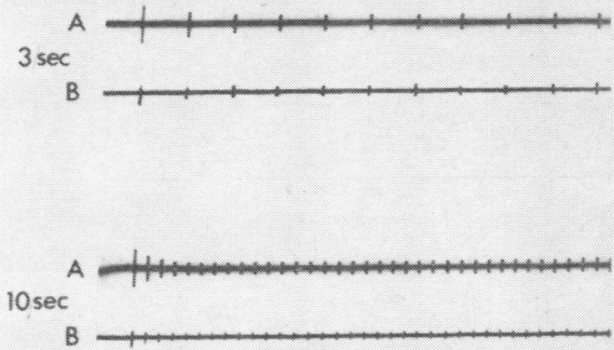

$50 \sec$
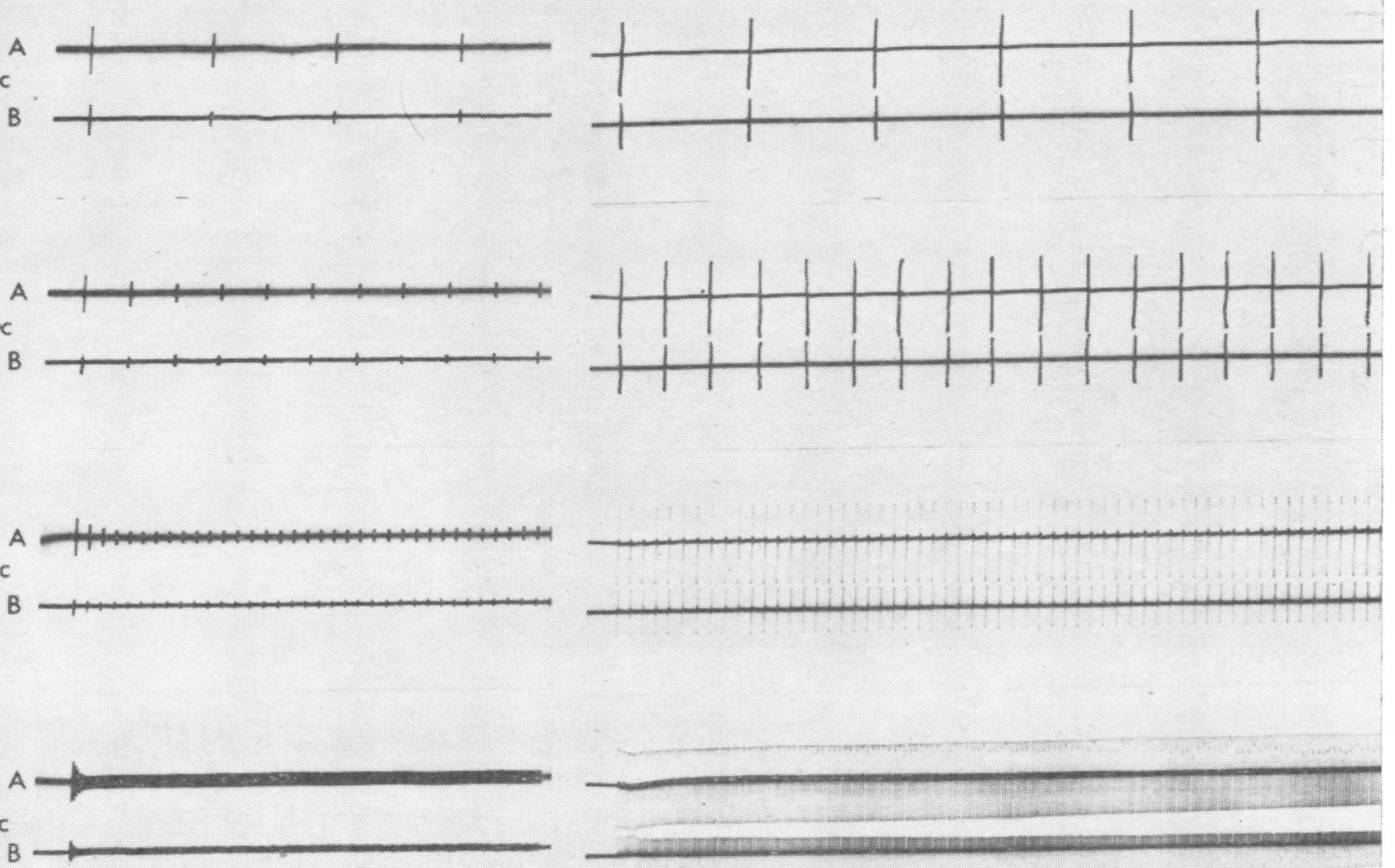

Immunised Guinea-pig
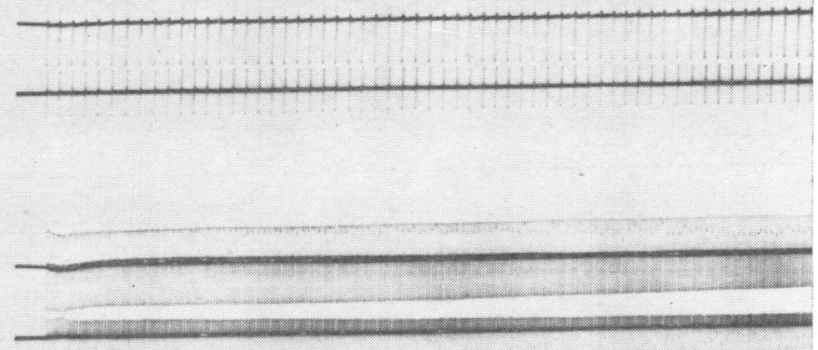

1.0sec
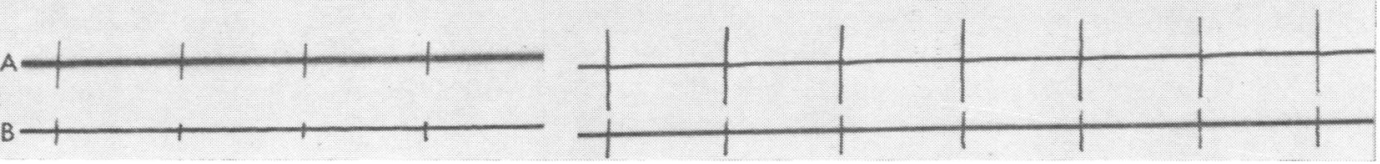

FIG. 1. Electrical response of the guinea-pig flexor digitorum at varying rates of stimulation (Retouched). One-third actual size.

did the injection of neostigmine produce any demonstrable difference between the two groups of animals.

A characteristic pattern of rapid and large decrement in height of the muscle response, not seen in any of the other groups of animals, was found after curarization (Fig. 1).

After tetanization at rates of stimulation of $50 / \mathrm{sec}$, immediate restimulation of the brachial plexus showed recovery of the muscle response to maximal height within one second in most animals, and no difference in this rate of recovery could be found between normal and immunized animals. Changes in maximal height of muscle response relative to those before tetanization varied from $-66 \%$ to $+54 \%$ and again represented electrode displacement.

Random recordings of intramuscular temperature in the flexor digitorum varied between 39 to $41^{\circ} \mathrm{C}$, which suggests that the variations in spike height were not due to changes in temperature. The immunized animals behaved in the same way irrespective of whether they received injections of muscle homogenate or only Freund's adjuvant, and whether given single or booster injections.

Adult animals immunized with muscle and thymus homogenates in the pilot experiment showed similar electromyographic responses, with no differences in response to normal animals.

HISTOLOGICAL FINDINGS Twenty-two immunized animals and six normal animals were examined. No lesions of muscle were found apart from very occasional collections of lymphocytes in association 


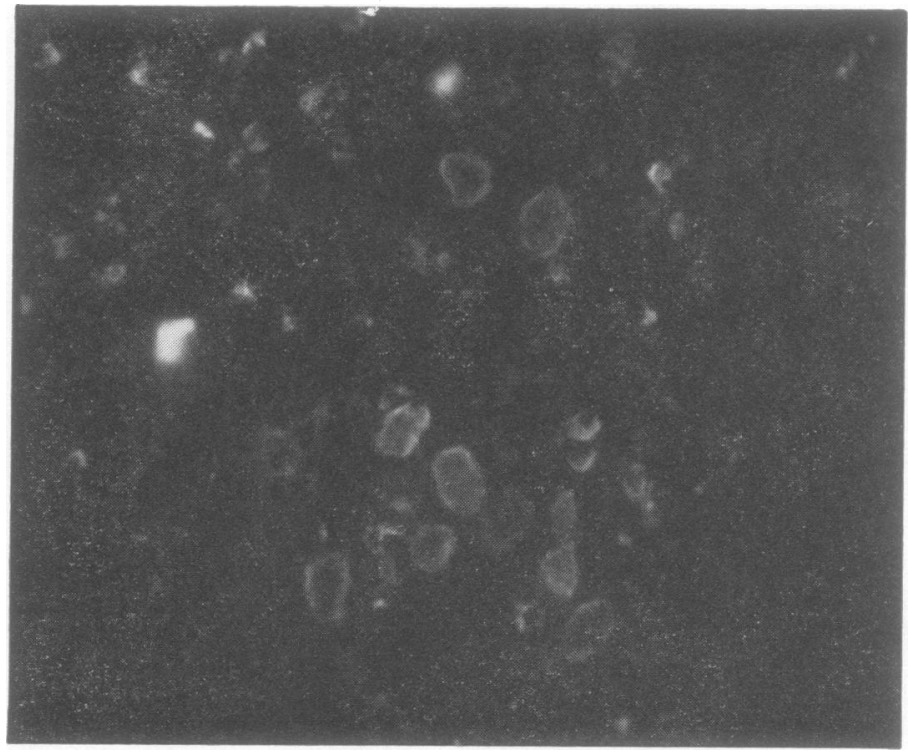

FIG. 2. Immunofluorescent staining of $\overrightarrow{\vec{D}}$ myoid cells in calf thymus with sera from 7 immunized guinea-pigs. $\times 500$.

with single degenerating muscle fibres in both normal and immunized animals.

IMMUNOLOGICAL FINDINGS Immunofluorescent staining Several patterns of fluorescent staining of calf muscle and thymic tissue were found. No staining was found using the sera of normal controls. Animals immunized by single foot-pad injections showed varying patterns of staining of myoid cells, epithelial cells, Hassall's corpuscles, and fib- rous septa (Figs. 2 and 3). Some animals showe staining only of myoid cells or Hassall's cor 음 puscles, others staining of several components? Animals receiving booster injections showee $?$ stronger staining patterns, notably with regard to sarcolemmal and septal staining, while those res ceiving Freund's adjuvant alone showed a fain $\overrightarrow{0}$ staining of lymphocytes and epithelial cells.

Gel diffusion Precipitation bands were found with three animals receiving booster doses of muscle

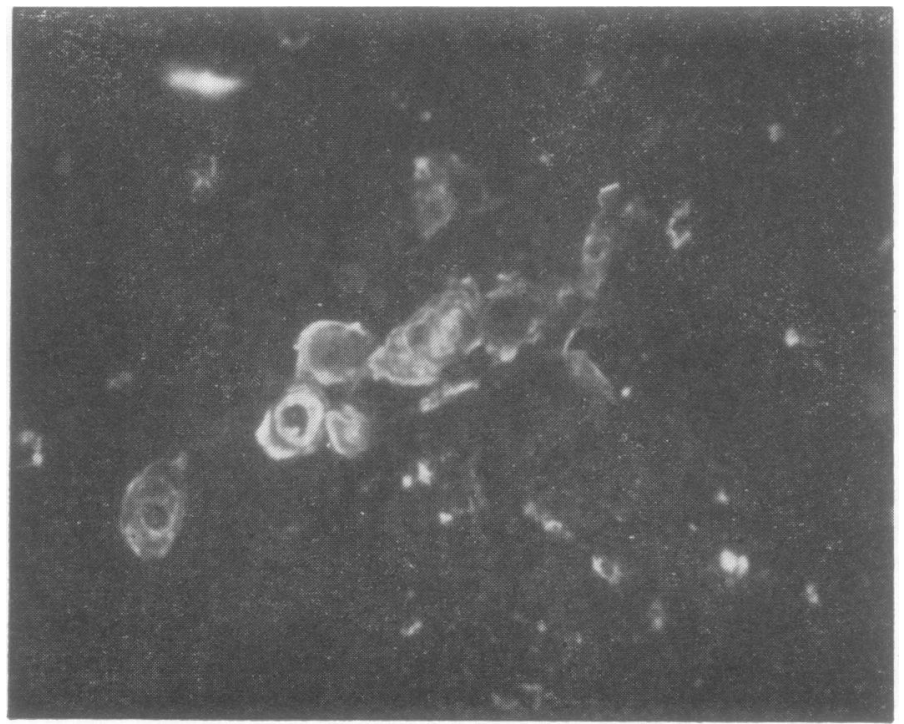

FIG. 3. Immunofluorescent staining of Hassall's corpuscle in calf thymus with sera from immunized guinea-pigs. $\times 500$. 
homogenate, by both Ouchterlony plate and tubeprecipitation methods. Animals receiving single injections of homogenate and normal controls failed to show precipitin bands.

COMMENTS We have been unable to find evidence of a myasthenic-like myopathy after single or booster injections of a heterologous muscle homogenate in guinea-pigs. Wide variations in the electromyographic response to repeated motor-nerve stimulation at $50 / \mathrm{sec}$ were found in immunized animals, but a similar wide range of variation was found in control animals. We found no characteristic decrease in muscle response to repeated stimulation as occurs in myasthenic patients and in curarized guinea-pigs. Recovery of maximal height of muscle response was prompt in all cases. Young animals, 6 to 9 months of age, were used, but in an earlier study using older guinea-pigs (12 to 18 months) essentially similar results were obtained.

Artefactual recordings due to displacement of intramuscular electrodes were often encountered. This is due to the isotonic nature of the muscle contraction, and prevented any comparative measurement of the first 10 muscle responses at rates of stimulation of $50 / \mathrm{sec}$ as had been employed by Goldstein and Whittingham (1966). The results of studies of the late fatigue of the muscle response at this rate of stimulation probably represents posttetanic exhaustion (Desmedt, 1966), and showed no differences between immunized and control animals.

Histological studies have not shown any significant lesions in muscle in the immunized animals.

Our immunological findings were similar to those of Goldstein and Whittingham (1966), and suggest that adequate immunization of the animals had been achieved. We did not observe any staining of muscle striations, but this could have been obscured by the marked sarcolemmal staining found with some sera. The findings of several patterns of fluorescent staining probably reflects the production of multiple antibodies by use of crude muscle homogenates.

\section{HISTOLOGY AND HISTOCHEMISTRY OF THYMUS}

Concurrent staining of striations of skeletal and cardiac muscle and certain cells in the thymus was observed by Van Der Geld, Feltkamp, Van Loghem, Oosterhuis, and Biemond (1963), and Van Der Geld et al. (1964), using the indirect immunofluorescent technique, and subsequently confirmed by other authors. Initially these cells were thought to be epithelial reticular cells but more recent studies identify them with muscle-like cells. The most comprehensive studies of these cells is that of Van de
Velde and Friedman $(1966,1967)$ who showed the cells to be present as elongate, striated myoid cells in the early foetal thymus of mammals, but subsequently losing their striations, becoming rounded, and disappearing before birth. In lower vertebrates they persist and can be found in the thymus of adult amphibians and reptiles.

Feltkamp-Vroom (1966) was able to demonstrate myoid cells in the thymus of the calf, chicken, and in two human thymuses. Henry $(1966,1968)$ has also found myoid cells in newborn and adult human thymus, but Mandel (1968) was able to find only one myoid cell in a large number of foetal and post-natal guinea-pig thymuses. We have examined the thymus of a number of different species for myoid cells by histological techniques, and immunofluorescent staining with myasthenic sera known to contain antibodies to muscle. The histochemistry of the thymus with particular regard to the myoid cells has also been investigated.

\section{METHODS}

Striated muscle and thymus from human stillborn infants (5), adult dogs (3), calves (6), lambs (3), newborn (4) and adult (3) rats, newborn (1) and adult (1) rabbits were examined. Tissues were fixed in formol saline, Zenker's formol, Carnay's fixative, and cold ethanol.

Conventional histological techniques were used employing haematoxylin and eosin, Gomori's trichrome, Mallory's trichrome, Papanicolaou technique, periodic acid Schiff reagent, and Heidenhain's haematoxylin. An azophloxine staining method for alpha proteins of the keratin-myosin-elastin-fibrin group described by Puchtler, Sweat, and Sesta (1966) was also employed.

Histochemical techniques for the demonstration of succinic, lactic, malic, glutamic, 5-hydroxybutyric, 6-phosphogluconic, glucose-6-phosphate, and alphaglycerophosphate dehydrogenases, di- and tri-phosphopyridine nucleotide dehydrogenases (DPNH, TPNH), adenosine tri-phosphatase (ATP'ase), 5-nucleotidase (5NT'ase), acid and alkaline phosphatases were employed as described by Barka and Anderson (1963).

The indirect immunofluorescent technique for the demonstration of anti-muscle antibodies in myasthenic sera was used (Coons, 1954). Thymus and muscle from the various animals studied were sectioned on a cryostat and stained concurrently with myasthenic sera known to contain muscle antibodies, and also myasthenic sera devoid of antibodies as controls. Sections were examined using a Zeiss fluorescence microscope for fluorescent staining of muscle or thymic cells.

Multiple sections were taken for both the histological and histochemical studies.

\section{RESULTS}

HISTOLOGICAL TECHNIQUES With the conventional histological techniques employed, large rounded cells with homogeneous cytoplasm and large vesi- 
cular nuclei were evident in the medulla of the calf thymuses, but not in any of the other animal thymuses studied. In the occasional cell a fibrillar pattern in the cytoplasm was evident with Gomori's and Mallory's trichromes, and the Papanicolaou technique. No elongate, striated muscle cells were recorded in any of the thymuses examined. All the histological techniques employed showed a corresponding staining pattern for striated muscle and the myoid cells of the thymus. With Heidenhain's haematoxylin, the myoid cells showed selective retention of stain on over-differentiation with ferric chloride.

Staining with azophloxine G.A. of sections fixed in Carnoy's fiuid showed good differential staining of myoid cells and Hassall's corpuscles in the thymus. Ultra-violet microscopy of these sections showed a marked red fluorescence of these structures, readily delimited from the non-fluorescent thymic lymphocytes and epithelial reticular cells. The cytoplasm of muscle and myoid cells stained a homogeneous red colour with this stain and did not allow visualization of striations (Fig. 4). Red blood cells were also stained.

Staining with periodic acid Schiff reagent showed a strongly positive pattern of staining of myoid cells corresponding with that of small striated muscle fibres. The action of diastase suggested the staining to be due to glycogen.

Using the previously mentioned histochemical techniques, calf thymus was found to show very little of the dehydrogenases in the cortex, and only slightly increased staining associated with epithelial cells in the medulla. Intense staining, however, was associated with blood vessels in the septa, myoid cells, and Hassall's corpuscles (Fig. 5). The myoid cells showed heavy staining identical with that of the small fibres of striated muscle, staining for lactic, succinic, and alpha-glycerophosphate dehydrogenases being especially strong, tut the Hassall's corpuscles varied considerably in the intensity with which they stained. It seemed to be the smaller corpuscles, apparently in the process of formation, that stained the more intensely, the central 'secretions' of the corpuscles being devoid of enzymes.

Staining for ATP'ase produced a diffuse staining of the thymus and, although Hassall's corpuscles could be occasionally identified by a more intense staining, myoid cells were difficult to identify. Hassall's corpuscles in some instances stained strongly for 5-nucleotidase, which otherwise seemed present only in the connective-tissue septa and did not seem to be present in myoid cells. Acid and alkaline phosphatase appeared to be restricted to cells in the connective-tissue septa.

Immunofluorescent staining of muscle striations occurred in all the species examined (calf, dog, lambo. rabbit, rat, guinea-pig, human stillborn) with thळ sera known to contain anti-muscle antibody but no $\overrightarrow{8}$ with sera devoid of such antibody. Myoid cells made evident by immunofluorescent staining with sera containing anti-muscle antibodies, occurred is calf thymus, but not in any of the other animat thymuses examined.

COMMENTS We have been able to demonstrate large

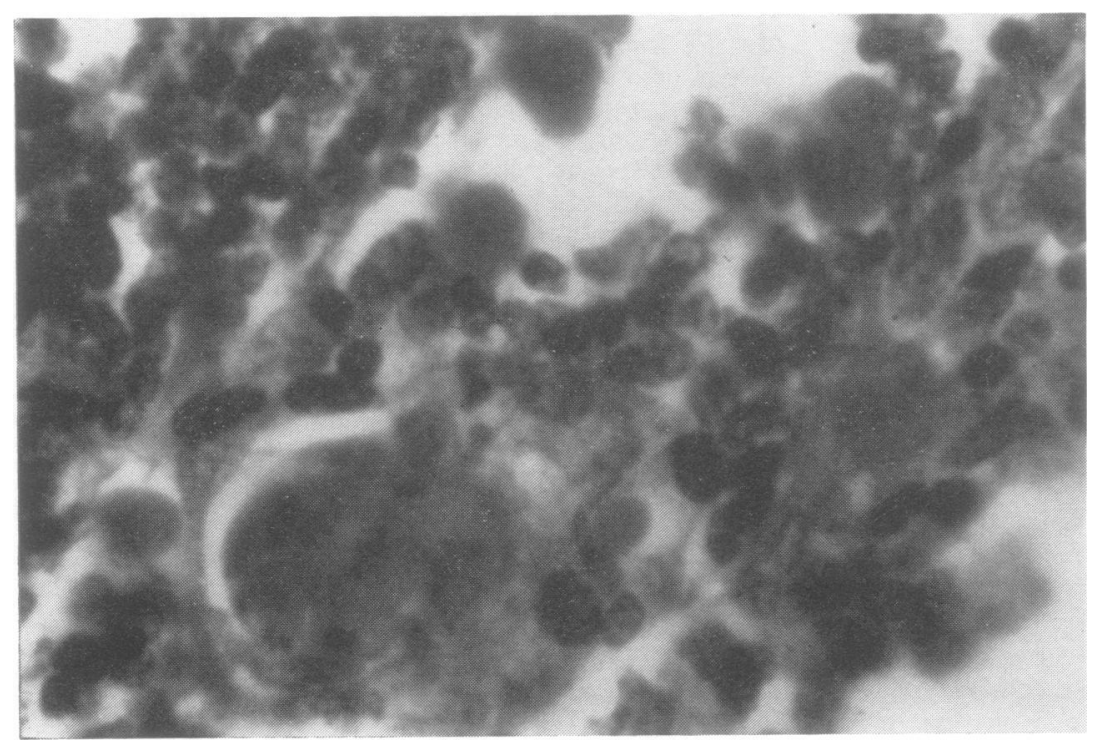

FIG. 4. Myoid cells and Hassall's corpuscle in calf thymus. Azophloxine G.A. $\times 1,000$. 


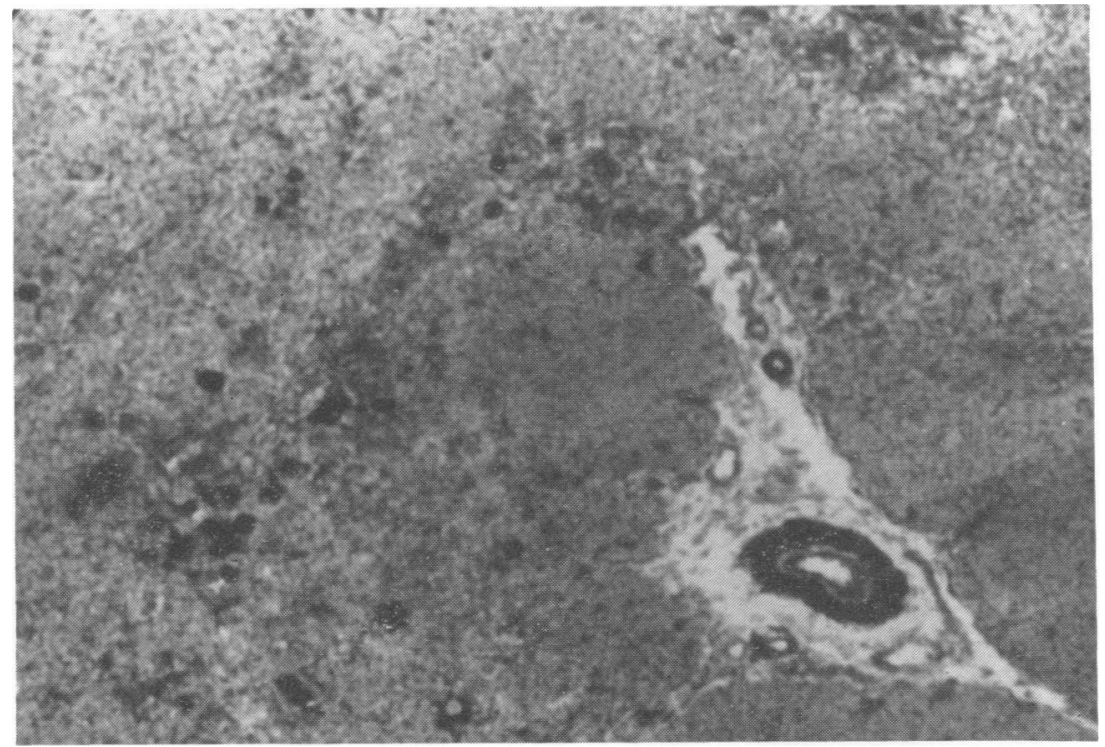

FIG. 5. Staining of calf thymus for lactic dehydrogenase. $\times 100$ rounded cells with vesicular nuclei in calf thymus, but not in the thymuses of dogs, rats, rabbits, lambs, or stillborn infants, using histological, histochemical, and immunofluorescent staining techniques. Such cells show staining properties identical with striated muscle, and can be shown to contain glycogen by the periodic acid Schiff technique, and a protein of the keratin-myosin-elastin-fibrin (KMEF) class, presumably myosin, by an azophloxine staining technique. Associated staining of Hassall's corpuscles by this latter method is presumably due to the keratin they contain.

Histochemical studies have shown these cells to be well endowed with enzyme dehydrogenases and to a lesser extent with ATP'ase, identical with the small rather than large striated muscle fibres (Engel, 1962). It is of interest that Hassall's corpuscles in early stages of formation also contain large amounts of dehydrogenases and ATP'ase, but in later stages seem to lose these enzymes. The high enzyme content of Hassall's corpuscle may well indicate a more active role for these structures than is generally assumed, as has been suggested by Blau and Veall (1967).

Our inability to find myoid cells in the human stillborn thymuses, contrary to the work of FeltkampVroom (1966) and Henry $(1966,1968)$, may be the result of the small number of such thymuses we have examined. It does seem, however, that they occur much less frequently in the human and other animals studied than in calf thymus, where myoid cells were consistently found in appreciable numbers.

Because of their abundance in calf thymus we have attempted to separate these myoid cells from thymus using an albumin gradient but without success. We have also been unable to culture them either from thymic cell suspensions or as explants.

\section{DISCUSSION}

Clinical evidence for a humoral factor in myasthenia is based on the observation that some newborn babies of myasthenic mothers suffer a transient 'neonatal myasthenia', attributed to a factor crossing the placenta from mother to child (Strickroot, Schaeffer, and Bergo, 1942; Stern, Hall, and Robinson, 1964). Stricker, Tholen, Massini, and Staub (1960) have shown clinical improvement in myasthenic patients subjected to haemodialysis.

Experimental evidence stems from the demonstration of factors present in sera of myasthenic patients (Wilson, Obrist, and Wilson, 1953; Parkes and McKinna, 1966) and in extracts of thymus (Nowell, Wilson, and Wilson, 1959; Goldstein, 1968) which have a neuromuscular-blocking effect on animal preparations. Some authors, however, have been unable to demonstrate such factors (Rider, 1955; Nastuk, Strauss, and Osserman, 1959).

The suggestion that autoimmune mechanisms might play a part in myasthenia has been based on clinical studies (Simpson, 1960, 1964) and the discovery of anti-muscle antibodies and other immunological abnormalities in myasthenic patients (Strauss et al., 1960, 1966; Beutner et al., 1962). The association of thymic abnormalities with myasthenia gravis and the discovery of the role of the 
thymus in immunological mechanisms (Miller, 1963) has further supported this hypothesis. Van Der Geld et al. (1963, 1964) and Van Der Geld and Strauss (1966) have identified myoid cells in the thymus reacting with anti-muscle antibody, and in lower vertebrates they have been found to have the sarcomeric and filamentous structure of muscle fibres. We have found these cells to be present in calf thymus, and to show the staining characteristics of muscle, to contain KMEF protein (probably myosin) and glycogen, and to have the histochemical characteristics of small striated-muscle fibres. Whether these cells provide the antigenic stimulus for the immunological abnormalities of myasthenia (Goldstein and Whittingham, 1966; Van de Velde and Friedman, 1966), or are simply remnants of branchial mesoderm, remains unanswered.

Despite individual case reports, myasthenia does not seem to show a strong relation to disorders linked with autoimmunity, other than thyroid disease (Wolf, Rowland, Schotland, McKinney, Hoefer, and Aranow, 1966). Increased incidence of thyroid, and, to a lesser extent, gastric parietal cell antibodies has been found in myasthenic patients (Simpson, 1964, 1966; Downes, Greenwood, and Wray, 1966; Wright and Kerr, 1967), and reflects histological findings (Schade, Owen, Smart, and Hall, 1960; Wright, Whitehead, Wangel, Salem, and Schiller, 1966). The increased incidence of antinuclear factor in myasthenic patients (Feltkamp, Van Der Geld, and Oosterhuis, 1963; Feltkamp, Van Der Geld, Oosterhuis, Den Oudsten, and Hijmans, 1964) seems to be a non-specific finding (Caspary, Gubbay, and Stern, 1964).

Recent studies of immunological abnormalities in myasthenia also suggest that, at least as far as the anti-muscle antibody is concerned, they do not play a primary role in the pathogenesis of myasthenia. Thus anti-muscle antibodies are not found to react with the myoneural junction (McFarlin, Engel, and Strauss, 1966). They are found in patients with thymomas in the absence of clinical myasthenia (McFarlin, Barlow, and Strauss, 1966) and their presence does not correlate with the clinical state of disease in neonatal myasthenia (Oosterhuis, Feltkamp, and Van Der Geld, 1966) or in thymectomized patients (Nastuk, Kessler, Grynbaum, Smith, and Herrmann, 1966).

As already mentioned, several authors have failed to find clinical muscle disease in animals immunized with muscle homogenates (Tal and Liban, 1962; Namba et al., 1964; Namba and Grob, 1966; Parkes, 1966; Simpson, 1966; Tolnai, 1966), although a myasthenia-like myopathy has been reported by Goldstein and Whittingham (1966). We have repeated and extended Goldstein and Whittingham's work without being able to find any myasthenia-like disease in guinea-pigs immunized with muscle homogenates.

Myasthenia gravis would thus seem to resemble organ-specific autoimmune diseases, exemplified by certain thyroid diseases and possibly Addison's disease, rather than non-organ-specific autoimmune disease (systemic lupus erythematosus). The presence of a factor in myasthenia gravis, thyrotoxicosis (McKenzie, 1964), and possibly pernicious anaemia that can cross the placenta of affected mothers to produce a transient disease in the newborn is a further feature in common. It is suggested that if autoimmune mechanisms are operative in myasthenia, an antibody resembling the long-acting thyroid stimulator (LATS) (Adams, 1965; Lipman, Green, Snyder, Nelson, and Solomon, 1967), rather than circulating antibody to muscle and myoid cells, is likely to be involved. This might also explain both the clinical and immunological associations of myasthenia gravis and thyroid disease.

\section{SUMMARY}

Experiments attempting to produce a myasthenialike myopathy in guinea-pigs by immunization with heterologous muscle homogenates are described. Antibodies to a number of muscle and thymic components were produced but no electromyographic changes resembling those of myasthenia gravis in man were observed. No muscle lesions were found on histological examination.

Histological and histochemical studies of thymus are described with particular reference to the nature of cells reacting with anti-muscle antibody from the sera of myasthenic patients. These cells were readily demonstrated in calf thymus but not in other animal thymuses, and showed the staining characteristics of small striated muscle fibres. Both myoid cells and small Hassall's corpuscles contained large amounts of dehydrogenase enzymes.

These findings are discussed with reference to the possible role of autoimmune mechanisms in the aetiology of myasthenia gravis.

The authors gratefully acknowledge a grant from the Wellcome Trust.

\section{REFERENCES}

Adams, D. D. (1965). Pathogenesis of the hyperthyroidism of Grave's disease. Brit. med. J., 1, 1015-1019.

Barka, T., and Anderson, P. J. (1963). Histochemistry: Theory, Practice and Bibliography. Harper and Row: New York.

Beutner, E. H., Witebsky, E., Ricken, D., and Adler, R. H. (1962). Studies on auto-antibodies in myasthenia gravis. J. Amer. med. Ass., 182, 46-58.

Blau, J. N., and Waksman, B. H. (1964). Immunological responses following injection of antigens in Freund's adjuvant into thymus and other tissues. Immunology, 7, 332-341. 
- and Veall, N. (1967). The uptake and localisation of proteins, Evan's blue and carbon black in the normal and pathological thymus of the guinea-pig. Ibid., 12, 363-372.

Caspary, E. A., Gubbay, S. S., and Stern, G. M. (1964). Circulating antibodies in polymyosit is and other muscle-wasting disorders. Lancet, 2, 941.

Coons, A. H. (1954). Labelled antigens and antibodies. Ann. Rev. Microbiol., 8, 333-352.

Desmedt, J. E. (1966). Presynaptic mechanisms in myasthenia gravis. Ann. N.Y. Acad. Sci., 135, 209-246.

Downes, J. M., Greenwood, B. M., and Wray, S. H. (1966). Autoimmune aspects of myasthenia gravis. Quart. J. Med., 35, $85-105$.

Engel, W. K. (1962). The essentiality of histo- and cyto-chemical studies of skeletal muscle in the investigation of neuromuscular disease. Neurology (Minneap.), 12, 778-794.

Feltkamp, T. E. W., Van Der Geld, H., and Oosterhuis, H. J. G. H. (1963). Studies on sera from cases of myasthenia gravis using the fluorescent antibody technique. Vox Sang. (Basel), 8, 317 327.

- $-1,-$ Den Oudsten, S. A., and Hijmans, W. (1964). The gravis. Acta rheum. scand., Suppl. No. 8, 9-16.

Feltkamp-Vroom, T. (1966). Myoid cells in human thymus. Lancet, 1,1320-1321.

Goldstein, G., and Whittingham, S. (1966). Experimental autoimmune thymitis. An animal model of human myasthenia gravis. Ibid., 2, 315-318.

(1968). The thymus and neuromuscular function. Ibid., 2, 119-122.

Henry, K. (1966). Mucin secretion and strained muscle in the human thymus. Ibid. 1, 183-185.

- (1968). Striated muscle in human thymus. Ibid., 1, 638-639.

Lipman, L. M., Green, D. L., Snyder, N. J., Nelson, J. C., and Solomon, D. H. (1967). Relationship of long-acting thyroid stimulator to the clinical features and course of Grave's disease. Amer. J. Med., 43, 486-498.

Mandel, N. (1968). Striated muscle in the cortex of foetal guinea-pig thymus. Nature (Lond.), 217, 276-277.

Marshall, A. H. E., and White, R. G. (1961a). Experimental thymic lesions resembling those of myasthenia gravis. Lancet, 1, 1030-1031.

Brit. J. exp. Path., 42, 379-385.

McFarlin, D. E., Engel, W. K., and Strauss, A. J. L. (1966). Does myasthenic serum bind to the neuromuscular junction? Ann. N.Y. Acad. Sci., 135, 656-663.

- Barlow, M., and Strauss, A. J. L. (1966). Antibodies to muscle and thymus in non-myasthenic patients with thymoma. Clinical evaluation. New Engl. J. Med., 275, 1321-1326.

McKenzie, J. M. (1964). Neonatal Graves' disease. J. clin. Endocr., 24, 660-668.

Miller, J. F. A. P. (1963). Immunity and the thymus. Lancet, 1, 43-45.

Namba, T., Himei, H., and Grob, D. (1964). Auto-immune phenomena in myasthenia gravis. Fed. Proc., 23, 342.

- , and Grob, D. (1966). Auto-antibodies and myasthenia gravis, with special reference to muscle ribonucleoprotein. Ann. N.Y. Acad. Sci., 135, 606-631.

Nastuk, W. L., Strauss, A J. L., and Osserman, K. E. (1959). Search for a neuromuscular blocking agent in the blood of patients with myasthenia gravis. Amer. J. Med., 26, 394-409.

- Kessler, H. J., Grynbaum, A., Smith, M., and Herrmann, C. (1966). Immunological changes following thymectomy in myasthenia gravis. Arch. Neurol. (Chic.), 15, 1-12.

Nowell, P. T., Wilson, A., and Wilson, H. (1959). Some effects of extracts of foetal whale thymus glands. Quart. J. exp. Physiol., 44, 229-238.

Oosterhuis, H. J. G. H., Feltkamp, T. E. W., and Van Der Geld, H. W. R. (1966). Muscle antibodies in myasthenic mothers and their babies. Lancet, 2, 1226-1227.

Ouchterlony, O. (1953). Antigen-antibody reactions in gels; types of reactions in coordinated systems of diffusion. Acta path. microbiol. scand., 32, 231-240.

Parkes, J. D. (1966). Attempted production of myasthenia gravis in the rat. Brit. J. exp. Path., 47, 577-585.
in the blood of patients with myasthenia gravis. Lancet, 1 , 388-391.

Puchtler, H., Sweat, F., and Sesta, J. J. (1966). Azophloxine GA, a selective stain for light and fluorescence microscopy of myoepithelial cells. Stain Technol., 41, 15-17.

Rider, J. A. (1955). The thymus and myasthenia gravis. (In the dis cussion). Amer. J. Med., 19, 700-702.

Schade, R. O. K., Owen, S. G., Smart, G. A., and Hall, R. (1960). The relation of thyroid auto-immunity to round-celled infiltration of the thyroid gland. J. clin. Path., 13, 499-501.

Sherman, J. D., Adner, M. M., and Dameshek, W. (1964). Direct injection of the thymus with antigenic substances. Proc. Soc. exp. Biol. (N.Y.), 115, 866-870.

,$- \quad \longrightarrow$, and $\longrightarrow$ (1965). Experimental production of germinal follicles in the thymus. Relationship of Hassall's corpuscles to germinal follicle formation. Ann. N.Y. Acad. Sci., 124, 105-117.

Simpson, J. A. (1960). Myasthenia gravis: a new hypothesis. Scot. med. J., 5, 419-436.

- (1964). Immunological disturbances in myasthenia gravis with a report of Hashimoto's disease developing after thymectomy. J. Neurol. Neurosurg. Psy'chiat., 27, 485-492.

- (1966). Myasthenia gravis as an auto-immune disease: clinical aspects. Ann. N.Y. Acad. Sci., 135, 506-516.

Stern, G. M., Hall, J. M., and Robinson, D. C. (1964). Neonatal myasthenia gravis. Brit. med. J., 2, 284-286.

Strauss, A. J. L., Seegal, B. C., Hsu, K. C., Burkholder, P. M., Nastuk, W. L., and Osserman, K.E. (1960). Immunofluorescence demonstration of a muscle-binding, complement-fixing serum globulin fraction in myasthenia gravis. Proc. Soc. exp. Biol. (N.Y.), 105, 184-191.

—-, Smith, C. W., Cage, G. W., Van Der Geld, H. W. R., McFarlin, D. E., and Barlow, M. (1966). Further studies on the specificity of presumed immune associations of myasthenia gravis and consideration of possible pathogenic implications. Ann. N.Y. Acad. Sci., 135, 557-579.

Stricker, E., Tholen, H., Massini, M. A., and Staub, H. (1960). The effect of haemodialysis in myasthenia gravis. J. Neurol. Neurosurg. Psychiat., 23, 291-294.

Strickroot, F. L., Schaeffer, R. L., and Bergo, H. L. (1942). Myasthenia gravis occurring in an infant of a myasthenic mother. J. Amer. med. Ass., 120, 1207-1209.

Tal, C., and Liban, E. (1962). Experimental production of muscular dystrophy-like lesions in rabbits and guinea pigs by an autoimmune process. Brit. J. exp. Path., 43, 525-529.

Tolnai, G. (1966). Muscle lesions in mice injected with isologous and homologous muscle extracts. Nature (Lond.), 212, 1429-1431.

Van Der Geld H. W. R., Feltkamp, T. E. W., Van Loghem, J. J., Oosterhuis, H. J. G. H., and Biemond, A. (1963). Multiple antibody production in myasthenia gravis. Lancet, 2, 373-375. -, and Oosterhuis, H. J. G. H. (1964). Reactivity of myasthenia gravis serum gamma-globulin with skeletal muscle and thymus demonstrated by immunofluorescence. Proc. Soc. exp. Biol. (N.Y.), 115, 782-785.

- - and Strauss, A. J. L. (1966). Myasthenia gravis. Immunological relationship between striated muscle and thymus. Lancet, 1, 57-60.

Van de Velde, R. L., and Friedman, N. B. (1966). The thymic 'myoidzellen' and myasthenia gravis. J. Amer. med. Ass., 198, 287-288. and - (1967). Muscular elements in the thymus. Anat. Rec., $157,392$.

Wilson, A., Obrist, A. R., and Wilson, H. (1953). Some effects of extracts of thymus glands removed from patients with myasthenia gravis. Lancet, 2, 368-371.

Wolf, S. M., Rowland, L. P., Schotland, D. L., McKinney, A. S., Hoefer, P. F. A., and Aranow, H. (1966). Myasthenia as an auto-immune disease: clinical aspects. Ann. N.Y. Acad. Sci., 135, 517-535.

Wright, R., Whitehead, R., Wangel, A. G., Salem, S. N., and Schiller, K. F. R. (1966). Auto-antibodies and microscopic appearance of gastric mucosa. Lancet, 1, 618-621.

, and Kerr, J. H. (1967). Autoimmunity in myasthenia gravis: a family study. Clin. exp. Iminunol., 2, 93-101. 